\title{
The prevalence of HIV in the sudden, unexplained and unexpected death population at the Pretoria Medico-Legal Laboratory
}

\begin{tabular}{|c|c|}
\hline \multicolumn{2}{|c|}{$\begin{array}{l}\text { Authors: } \\
\text { Neil K. Morris }{ }^{1} \text { (D) } \\
\text { Lorraine du Toit-Prinsloo }^{1} \\
\text { Lynne Webber }^{2} \\
\text { Gert Saayman }^{1}\end{array}$} \\
\hline \multicolumn{2}{|c|}{$\begin{array}{l}\text { Affiliations: } \\
{ }^{1} \text { Department of Forensic } \\
\text { Medicine, University of } \\
\text { Pretoria, South Africa }\end{array}$} \\
\hline \multicolumn{2}{|c|}{$\begin{array}{l}{ }^{2} \text { Department Medical } \\
\text { Virology, University of } \\
\text { Pretoria, South Africa }\end{array}$} \\
\hline \multicolumn{2}{|c|}{$\begin{array}{l}\text { Corresponding author: } \\
\text { Neil Morris, } \\
\text { neil.morris@up.ac.za }\end{array}$} \\
\hline \multicolumn{2}{|c|}{$\begin{array}{l}\text { Dates: } \\
\text { Received: } 21 \text { Sept. } 2015 \\
\text { Accepted: } 22 \text { Mar. } 2016 \\
\text { Published: } 31 \text { May } 2016\end{array}$} \\
\hline \multicolumn{2}{|c|}{$\begin{array}{l}\text { How to cite this article: } \\
\text { Morris NK, Du Toit-Prinsloo L, } \\
\text { Webber L, Saayman G. The } \\
\text { prevalence of HIV in the } \\
\text { sudden, unexplained and } \\
\text { unexpected death population } \\
\text { at the Pretoria Medico-Legal } \\
\text { Laboratory. S Afr J HIV Med. } \\
\text { 2016;17(1), a424. http://dx. } \\
\text { doi.org/10.4102/sajhivmed. } \\
\text { v17i1.424 }\end{array}$} \\
\hline \multicolumn{2}{|c|}{$\begin{array}{l}\text { Copyright: } \\
\text { (C) 2016. The Authors. } \\
\text { Licensee: AOSIS. This } \\
\text { is licensed under the } \\
\text { Creative Commons } \\
\text { Attribution License. }\end{array}$} \\
\hline \multicolumn{2}{|l|}{ Read online: } \\
\hline 回点的回 & $\begin{array}{l}\text { Scan this QR } \\
\text { code with your } \\
\text { smart phone or } \\
\text { mobile device } \\
\text { to read online. }\end{array}$ \\
\hline
\end{tabular}

Purpose: To determine the prevalence of HIV in the sudden, unexplained and unexpected (SUU) death population admitted to the Pretoria Medico-Legal Laboratory.

Methods: This study was conducted at the Pretoria Medico-Legal Laboratory. Blood samples were obtained from decedents who died suddenly and/or unexpectedly, during autopsy, by a forensic pathologist. Sample collection continued until 100 valid samples were analysed for HIV antibodies. The data collected included demographic details and case-related information.

Results and Conclusion: SUU deaths accounted for $14 \%$ of all cases admitted to the Pretoria Medico-Legal Laboratory. The HIV prevalence in the SUU deaths was $43 \%$, which is $17 \%$ higher than the general mortuary population in Pretoria $(p=0.0045)$. The majority of these deaths were due to respiratory disease processes, with 12 cases having HIV/TB co-infection.

\section{Introduction}

There are numerous definitions for sudden deaths. All of the definitions include two main parameters. They relate to the time from the onset of symptoms and signs, and the time of death. ${ }^{1}$ These times vary between zero, 1, 6 and 24 h. ${ }^{1}$ The WHO defines a sudden death as a death occurring within 24 hours after the onset of symptoms. ${ }^{2}$ Byard classified these deaths into three categories: those individuals who were apparently completely well and died suddenly; those who were mildly unwell; and those with known serious disease processes but were stable on treatment. ${ }^{1}$ The admission of cases of sudden, unexpected and/or unexplained deaths (SUU-Deaths) to medico-legal mortuaries is a well-known worldwide phenomenon, and in many of these cases an inadequate history is present at the time of the investigation. ${ }^{3}$

In South Africa, the performance of medico-legal autopsies is regulated by the Inquests Act (No. 58 of 1959). The definition of unnatural deaths is in the Regulations Regarding the Rendering of Forensic Pathology Service (R636) in accordance with Chapter 11 of the National Health Act (No. 61 of 2003). These include cases 'where the death is sudden and unexpected, or unexplained, or where the cause of death is not apparent'.

SUU-Deaths are considered to be some of the most challenging autopsies that can be conducted by pathologists. ${ }^{3}$ In many of these cases, it is difficult to ascertain whether or not the person died from a disease process found at autopsy or as a result thereof. ${ }^{4}$

HIV can cause death of an individual in numerous different ways including AIDS, accelerated cardiovascular disease, malignancies and opportunistic infections. ${ }^{5}$ AIDS is regarded as being the number one cause of death in HIV patients. ${ }^{6}$ Tseng et al. indicated that sudden cardiac deaths in HIV-positive individuals accounted for $86 \%$ of all cardiac deaths with a mean rate of 2.6 per 1000 person-years. $^{6}$

Antiretroviral therapies have been associated, in a number of studies, with the increased risk of cardiovascular disease. ${ }^{7,8}$ It was documented that: 'Increased exposure to protease inhibitors is associated with an increased risk of myocardial infarction, which is partly explained by dyslipidaemia'. ${ }^{9}$ TB and HIV co-infection may also be linked to SUU-Death. TB and HIV co-infected patients have a five times greater risk of dying within 2 years of receiving TB treatment. ${ }^{10}$ Other studies have determined that $31 \%$ of all new TB cases in the African region can be attributed to HIV infection: 'TB was the cause of $11 \%$ of all adult AIDS-related deaths'. In South Africa, it was estimated that there were 2 million co-infected adults in 2003.11,12 
South Africa has a jaded past with misinformation and the stigmatisation of HIV-positive individuals. ${ }^{13,14}$ Due to these social factors, the disclosure of an accurate medical history is not forthcoming in cases of SUU-Death. This ends up hindering the medico-legal investigation of the death.

South Africa had a population of 49320500 people as of mid-2009, and $10.6 \%$ of the population was HIV-positive. ${ }^{15}$ The burden of the disease on the state is large and costly. In order to minimise the consequences of the pandemic, every possible chance to understand and refine the information, used to make important prevention and treatment decisions, needs to be implemented and assessed.

This study seeks to provide relevant statistical information on the HIV prevalence rate in the SUU-Death population of the Pretoria Medico-Legal Laboratory (MLL). The results of this study could also provide additional insight into the epidemiology of the virus and the SUU-Death population. This can facilitate a protocol change in the handling of the SUU-Death population admitted to the Pretoria MLL. This would be to implement standardised HIV testing in SUU-Death cases, which, in turn, will have budgetary and policy implications for the Forensic Pathology Service (FPS).

\section{Materials and methods Study population}

This study was conducted at the Pretoria MLL. Pretoria is the capital city of South Africa with a population of approximately $2553648 .{ }^{16}$ The Pretoria MLL admits approximately 2500 cases each year, and full autopsies are conducted in more than $90 \%$ of the cases admitted. A previous study conducted at the Pretoria MLL indicated that the HIV prevalence of the general mortuary population was $26 \% .{ }^{17}$ The SUU-Death population makes up $14 \%$ of the general mortuary population. Samples were collected until the study had obtained 100 valid results.

\section{Method}

Blood samples were obtained from decedents who died suddenly and/or unexpectedly. This was done during autopsy, by a forensic pathologist. Sample collection continued until 100 valid samples were analysed. A study and funding limitation was that only 100 samples were to be collected.

The processing of blood samples was done by the following standardised testing procedures developed and used in the NHLS Tshwane virology research department:

- After centrifugation of whole blood, the serum was used to run the test in order to minimise the effect that haemolysed blood has on test strips.

- The screening test used was the Determine ${ }^{\mathrm{TM}} \mathrm{HIV}-1 / 2$ $\mathrm{Ag} / \mathrm{Ab}$ Combo assay, and the confirmatory test used was the HIV Combi, Cobas E, Elecsys and Modular (Roche). ${ }^{18}$

\section{Exclusionary criteria}

The following cases were excluded: if age was less than 9 months because of the possible residual positive reaction to the mothers' antibodies in the child ${ }^{19,20}$; and if it was not possible to obtain a sample due to post-mortem changes (decomposition) or charring of the remains.

\section{Data collection and analysis}

The data collected included demographic details and caserelated information. Confidentiality was ensured, and the study proposal was approved by the University of Pretoria's Faculty of Health Sciences Research Ethics Committee and the MSc Committee.

The statistical analysis was done in conjunction with the Department of Statistics at the University of Pretoria. The null hypothesis was that the prevalence of HIV in the Pretoria MLL SUU-Death population should not deviate from that of the general Pretoria MLL population. The statistical programme $\mathrm{SAS}^{\circledR}$ was used for the analysis of data.

\section{Results}

The data collection took approximately 10 months to complete in 2009. A total of 130 samples were collected, of which 100 samples yielded a valid HIV result. The remaining 30 samples when tested provided an invalid result on the test (the absence of a test result). This was discussed in a previous study, and it could be caused by an increased post-mortem interval. ${ }^{17}$

\section{Demographic details}

Table 1 lists the results of the HIV screening and confirmatory testing that was done at the NHLS Tshwane medical virology laboratory. A total of 30 invalid test results were documented; these translate into $25 \%$ of all samples. Of the viable samples, 43 (43\%) were HIV-positive and 57 (57\%) were HIV-negative.

Table 2 lists the gender and race distribution of the HIVpositive cases. Twenty-one per cent (21 cases) of the SUUDeath sample population was female and 79\% (79 cases) was male. Of the female demographic fraction, the HIV-positive cases made up $62 \%$ (13 cases) of the total valid samples. In the male demographic fraction, the HIV prevalence rate was $38 \%$ (30 cases).

The race demographics for the SUU-Death cases are listed in Table 2. Of the total sample population, Asian individuals made up $2 \%$ ( 2 cases), with none of them being documented

TABLE 1: Total sudden, unexplained and unexpected death cases and HIV prevalence information in the Pretoria Medico-Legal Laboratory.

\begin{tabular}{lcccc}
\hline Result & $\begin{array}{c}\text { Number } \\
\text { of cases }\end{array}$ & $\mathbf{\%}$ & $\begin{array}{c}\text { Number of } \\
\text { valid samples }\end{array}$ & $\mathbf{\%}$ \\
\hline HIV-positive & 43 & 32 & 43 & 43 \\
HIV-negative & 57 & 43 & 57 & 57 \\
Invalid & 30 & 25 & - & 0 \\
\hline Total & 130 & - & 100 & - \\
\hline
\end{tabular}


TABLE 2: Gender and race demographics for sudden, unexplained and unexpected death cases.

\begin{tabular}{llccccc}
\hline $\begin{array}{l}\text { Demographic } \\
\text { parameters }\end{array}$ & Variable & $\begin{array}{c}\text { HIV- } \\
\text { positive }\end{array}$ & $\begin{array}{c}\text { HIV- } \\
\text { negative }\end{array}$ & $\%$ & $\begin{array}{c}\text { Total valid } \\
\text { samples }\end{array}$ \\
\hline Gender & Female & 13 & 62 & 8 & 38 & 21 \\
Total & Male & 30 & 38 & 49 & 62 & 79 \\
\hline Race & Asian & 0 & 0 & 2 & 100 & 2 \\
& Black & 40 & 51 & 39 & 49 & 79 \\
& Mixed race & 0 & 0 & 0 & 0 & 0 \\
& White & 3 & 16 & 16 & 84 & 19 \\
Total & & $\mathbf{4 3}$ & - & $\mathbf{5 7}$ & - & $\mathbf{1 0 0}$ \\
\hline
\end{tabular}

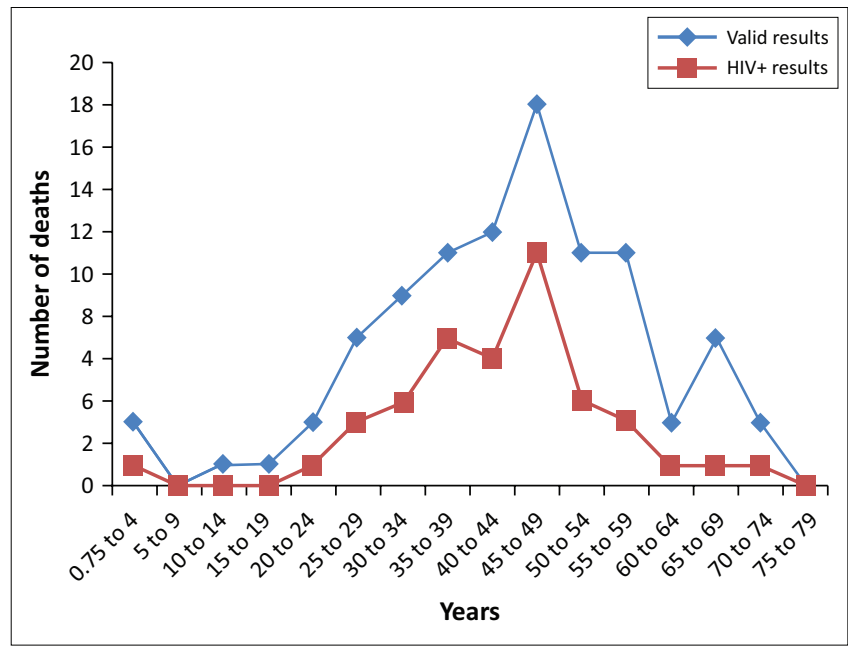

Valid test results: $n=100$.

HIV+ test results: $n=43$.

FIGURE 1: Age distribution of the valid sudden, unexplained and unexpected death samples and the HIV-positive results.

as HIV-positive. Black population group made up 79\% (79 cases), and the prevalence of HIV was 51\% (40 cases). No individuals classified as 'mixed race' were documented in this study. White South Africans made up 19\% (19 cases) of the SUU-Death population, and the HIV prevalence is $16 \%$ (3 cases) in this group.

The age of individual cases in this study ranged from 9 months to 74 years (Figure 1). Data were divided into categories with a 5-year interval between the groupings. Positive HIV immune assay results were obtained only from samples in the 9 months -74 years range, resulting in a $43 \%$ rate of infection across the entire Pretoria MLL SUUDeath population. The average age for the valid sample population was 43 years. The average age for females was 39.0 years and for males 44.9 years. The average age in the males from the black population group was 45.5 years and in the males from the white population group was 42.6 years. The average age in the females from the white and black population groups was 37.2 years and 39.3 years, respectively.

\section{Cause of death}

The causes of death are summarised in Table 3 below. The majority of the deaths were due to respiratory disease processes (31 in total) with 12 cases of TB, 15 cases of
TABLE 3: Causes of death.

\begin{tabular}{lc}
\hline Cause of death & Number of cases \\
\hline Cardiovascular diseases & 17 \\
Pulmonary diseases & 19 \\
Tuberculosis & 12 \\
Central nervous system & 4 \\
AIDS & 1 \\
Genito-urinary system & 2 \\
Gastro-intestinal tract & 6 \\
Natural causes & 6 \\
Non-natural causes & 11 \\
Pregnancy-associated disease & 1 \\
Unascertained & 14 \\
Under investigation & 7 \\
\hline
\end{tabular}

$n=100$.

TABLE 4: Chi-square analysis of the general population HIV statistics and sudden, unexplained and unexpected death HIV prevalence statistics.

\begin{tabular}{lccc}
\hline $\begin{array}{l}\text { General mortuary } \\
\text { population's HIV } \\
\text { prevalence \% }\end{array}$ & $\begin{array}{c}\text { General mortuary } \\
\text { population's HIV } \\
\text { prevalence }\end{array}$ & $\begin{array}{c}\text { SUU-Death } \\
\text { population's HIV } \\
\text { prevalence \% }\end{array}$ & $\begin{array}{c}\text { Chi-square } \\
\text { analysis }(p)\end{array}$ \\
\hline 26 & 17 & 43 & 0.0045 \\
\hline
\end{tabular}

bronchopneumonia, 2 pulmonary thrombo-embolism cases and 1 each of asthma and small-cell lung carcinoma (19 cases of pulmonary disease). Cardiovascular disease processes included six cases of ischaemic heart disease, two cases of myocarditis and nine cases of cardiomyopathy. In the central nervous system, one case each of meningitis and sudden unexpected death in epilepsy (SUDEP) and two cases of haemorrhagic cerebrovascular incident were present; only one case was signed out as being due to AIDS. In 11 cases which presented as sudden unexpected deaths, unnatural causes of death was identified, which included acute alcohol poisoning, carbon monoxide poisoning and trauma.

The prevalence of both the general populations HIV statistics (previously conducted study ${ }^{17}$ ) and the SUU-Death populations HIV statistics were compared in Table 4 with a chi-squared analysis, which yielded a statistically significant $p$-value of $0.0045 .^{17}$

\section{Discussion}

The HIV prevalence in the SUU-Death population at the Pretoria MLL is $43 \%$. This is significantly higher than the HIV prevalence in the general mortuary population at the Pretoria MLL (26\%), translating into a $17 \%$ difference in prevalence between the two groups. ${ }^{17}$ This was determined to be statistically significant. White South Africans account for $18 \%$ of the general mortuary population and their HIV prevalence was $8 \%$ in the general mortuary population. ${ }^{17}$ However, in the SUU-Death population they accounted for an unexpected $19 \%$ of the population and had an HIV prevalence of $16 \%$. Black South Africans accounted for $76 \%$ of the general mortuary population with an HIV prevalence of $32 \% .{ }^{17}$ In the SUU-Death population, black South Africans accounted for $79 \%$ of the population but had an HIV prevalence of $51 \%$. The concerning factor is that there are such large numbers of HIVpositive cases being admitted to the Pretoria MLL and that $\mathrm{HIV}$ is not being routinely tested for in the mortuary setting. 
In contrast to the study by Christiansen in which he found the top three causes of SUU-Death - cardiovascular, malignancy and infection, the majority of our cases died from respiratory disease processes followed by cardiovascular disease. TB accounted for 12 of the 31 respiratory disease-related deaths. In South Africa's Millennium Development Goals, Goal 6 declares that there is a co-infection rate of $70 \%$ with TB and HIV. $^{21}$ In a report by Statistics South Africa in 2009, TB accounted for $12 \%$ of all deaths, influenza and/or pneumonia $7.5 \%$ and HIV $3.1 \%,{ }^{22}$ thus giving us a context for this difference in profile.

TB-HIV co-infection and antiretroviral treatment side effects are two possible explanations that warrant further investigation in this subpopulation. Tseng et al. indicated that sudden cardiac deaths in HIV-positive individuals accounted for $86 \%$ of all cardiac deaths with a mean rate of 2.6 per 1000 person-years. ${ }^{6}$ In our study, cardiovascular diseases accounted for $17 \%$ of the cases with the majority being due to cardiomyopathy.

SUU-Deaths are a challenging autopsy and need to be approached with caution and the right amount of scepticism. The purpose of these autopsies is firstly to rule out an unnatural cause of death and secondly to provide, if possible, the cause of death even if it is natural.

The value of post-mortem HIV testing as an ancillary investigative technique to assist in the decision-making process and diagnosis of the cause of death should be further investigated. These cases are often admitted with no available history as the next of kin is not known or the medical history is incomplete. An HIV test can be helpful in determining the cause of death.

Unfortunately in South Africa, HIV has not been routinely tested for in the SUU-Death cases, and as a result statistics and observations regarding this challenging autopsy population have left a number of unanswered questions. This research study has attempted to address these questions and has shown that the analysis and observations provided by this testing provide an accurate well-documented source of information to facilitate the complex decisions that need to be taken in determining the cause of death and ultimately in our fight with regard to the HIV pandemic.

If medical records, post-mortem HIV test results and eyewitness testimony are made available before autopsy, a death scene investigator (DSI) can collect the relevant records and information and present them to the forensic pathologist along with the HIV test results. This would simplify the postmortem examination for the forensic pathologist and facilitate a possible reduction in the number of SUU-Death cases admitted to the Pretoria MLL for a full autopsy. A reduction in SUU-Death cases could save the FPS a considerable amount of money and decrease the workload. This will ultimately streamline the provision of FPSs in the Pretoria MLL. A spin-off of testing for HIV routinely would be that there is a database of results that could be used to better understand HIV in the PM setting.

\section{Conclusion}

SUU-Deaths accounted for $14 \%$ of all cases admitted to the Pretoria MLL. The HIV prevalence in the SUU deaths was $43 \%$, which is $17 \%$ higher than the general mortuary population in Pretoria $(p=0.0045)$. The majority of these deaths were due to respiratory disease processes with 12 cases having HIV-TB co-infection.

This study demonstrates the value of testing the SUUDeath population for HIV at autopsy. Further research recommendations are that research should be conducted in the implementation of routine HIV testing and testing for which stage of infection the HIV-positive SUU-Death cases are in. Screening for resistance and antiretrovirals could also be undertaken to determine if the person was on treatment at the time of death.

\section{Acknowledgements Competing interests}

The authors declare that they have no financial or personal relationships which may have inappropriately influenced them in writing this article.

\section{Authors' contributions}

N.K.M. was the project leader, did all the sample collection, analysed the data and prepared the manuscript. L.d.T-P. was the supervisor and made conceptual and editorial contributions. L.W. assisted in the HIV testing and made conceptual contributions. G.S. made conceptual and editorial contributions.

\section{References}

1. Byard RW. Sudden death in the young. New York: Cambridge University Press; 2010.

2. World Health Organisation. International Classification of Diseases. 2010 [cited 2011 Dec 08]. Available from: http://www.who.int/classifications/icd/en/

3. Christiansen LR, Collins KA. Natural death in the forensic setting: A study and approach to the autopsy. Am J Forensic Med Pathol. 2007;28(1):20-23. http:// dx.doi.org/10.1097/01.paf.0000233553.19938.a0

4. Republic of South Africa. Regulations regarding the rendering of Forensic Pathology Services. National Health Act (61 of 2003); 2005.

5. Spencer DC. The clinical practice of HIV medicine. Johannesburg, South Africa: Goldstream Books; 2005; p. 99, p. 139.

6. Tseng ZH, Secemsky EA, Dowdy D, et al. Sudden cardiac death in patients with human immunodeficiency virus infection. J Am Coll Cardiol. 2012;59(21): 1891-1896. http://dx.doi.org/10.1016/j.jacc.2012.02.024

7. DAD Study Group. Cardiovascular disease risk factors in HIV patients - association with antiretroviral therapy. AIDS 2003;17(8):1179. http://dx.doi.org/10.1097/ 00002030-200305230-00010

8. Koppel K, Görana B, Jovanb R. Sudden cardiac death in a patient on 2 years of highly active antiretroviral treatment: A case report. AIDS. 1999;13(14):1993. http://dx.doi.org/10.1097/00002030-199910010-00033

9. DAD Study Group. Class of antiretroviral drugs and the risk of myocardial infarction. N Engl J Med. 2007;356:1723-1735. http://dx.doi.org/10.1056/ NEJMoa062744

10. Elliott AM, Halwiindi B, Hayes RJ, et al. The impact of human immunodeficiency virus on mortality of patients treated for tuberculosis in a cohort study in Zambia. Trans R Soc Trop Med Hyg. 1995;89(1):78-82.

11. Djoba Siawaya JF, Ruhwald M, Eugen-Olsen J, Walzl G. Correlates for disease progression and prognosis during concurrent HIV/TB infection. Int J Infect Dis. 2007;11(4):289-299. http://dx.doi.org/10.1016/j.ijid.2007.02.001 
12. Corbett $\mathrm{E}$, Watt $\mathrm{CJ}$, Walker N, et al. The growing burden of tuberculosis. Global trends and interactions with the HIV epidemic. Arch Intern Med. 2003;163:1009. http://dx.doi.org/10.1001/archinte.163.9.1009

13. Van Rijn K. The politics of uncertainty: The AIDS debate, Thabo Mbeki and the South African Government Response. Soc Hist Med. 2006;19(3):521. http://dx. doi.org/10.1093/shm/hkl077

14. Keikelame MJ, Murphy CK, Ringheim KE, Woldehanna S. Perceptions of HIV/AIDS leaders about faith-based organisations on HIV/AIDS stigma in South Africa. AJAR. 2010;9(1):63. http://dx.doi.org/10.2989/16085906.2010.48457

15. Statistics South Africa. Mid-year population estimates for 2009. 27 July 2009; P0302.

16. The Demographics chapter â - Institute of Race Relations; 2014 [cited 2014 Dec 27] Available from: http://irr.org.za/reports-and-publications/south-africa-survey/ south-africa-survey-2012/01-demographics

17. Morris N, Du Toit-Prinsloo L, Webber L, Saayman G. The prevalence of HIV in Pretoria's Medico-Legal Laboratory cases, RSA, in 2009. Occup Health South Afr. 2014;20(2):4.
18. Ly TD, Laperche S, Brennan C, et al. Evaluation of the sensitivity and specificity of six HIV combined p24 antigen and antibody assays. J Virol Methods. 2004 12/15;122(2):185-194.

19. Sherman GG, Lilian RR, Coovadia AH. The performance of 5 rapid HIV tests using whole blood in infants and children: Selecting a test to achieve the clinical objective. Pediatr Infect Dis J. 2012;31(3):267-272. http://dx.doi.org/10.1097/ INF.0b013e31823752a0

20. World Health Organization. WHO recommendations on the diagnosis of HIV infection in infants and children. 2010 [cited 2016 Feb 04]. Available from: http:// whqlibdoc.who.int/publications/2010/9789241599085_eng.pdf

21. Council SANA. The HIV \& AIDS and STI strategic plan for South Africa 2007-2011. 2009 [cited 2014 Oct 27]. Available from: http://beta2.statssa.gov.za/MDG/2010 MDG_GOAL_6_COMBAT_HIV_AIDS_MALARIA_AND_OTHER_DISEASES.pdf

22. Statistics South Africa. P0309.3 - Mortality and causes of death in South Africa: Findings from death notification, 2009. Statistics RSA; 2009 [cited 2014 Nov 06] Available from: http://www.statssa.gov.za/publications/statsdownload.asp?PPN= $\mathrm{P} 0309.3 \& \mathrm{SCH}=5097$ 